\title{
Study Of Cogency Of Clonidine Added To Bupivacaine And Bupivacaine Alone In Supraclavicular Plexus Brachialis Block For Higher Limb Surgery Dr Evgeni Axton, Dr Austin Barnett
}

\author{
Department Of Anaesthesiology Orenburg State Medical University, Russia
}

\begin{abstract}
The aim was to evaluate the clinical effects of clonidine as an adjuvant to supraclavicular brachial plexus block with $0.5 \%$ L-bupivacaine. Permission from Institutional ethical committee was taken before starting the study and informed written consent was taken from all patients. After carefully explaining the procedure to the patients, they were divided randomly into 2 groups by using table of random numbers. Group $A(n=30)$ recieved $30 \mathrm{ml}$ of $0.5 \%$ levobupivacaine with 1 $\mathrm{ml}$ normal saline. Group B $(\mathrm{n}=30)$ received $30 \mathrm{ml}$ of $0.5 \%$ levobupivacaine with $0.3 \mathrm{ml}$ clonidine $(50 \mu \mathrm{g})$ diluted with normal saline to make up the solution $1 \mathrm{ml}$. Drugs were prepared by anesthetist who was not involved in the proceedings of the study.
\end{abstract}

Keywords: Catapres, Bupivacaine, Supraclavicular plexus brachialis block.

\section{Introduction}

A peripheral nerve block (PNB) is that the injection of a neighborhood anesthetic around a nerve or cluster of nerves for blockade of electrical discharge physical phenomenon, inflicting temporary physiological condition and loss of sensory and motor operate. Peripheral neural blockade is currently a well accepted part of comprehensive anesthetic care. Peripheral nerve blocks area unit price effective anesthetic techniques accustomed give sensible physiological state and physiological condition whereas avoiding airway instrumentation as compared to hemodynamic consequences of general and neuraxialanaesthesia 1and for this reason all round the world, interest in regional anesthesia is growing chop-chop. Patient satisfaction associate degreed a growing demand for favorable post operative recovery profile have resulted in an 


\section{THE AMERICAN JOURNAL OF}

MEDICAL SCIENCES AND

VOLUME01 ISSUE04

\section{PHARMACEUTICAL RESEARCH}

increasing

demand

for

regional

anesthesia.

Concurrent sympathetic blockade reduces post-op pain, vasospasm and edema. presently bupivacaine is that the most often used anaesthetic agent as a result of long length.2,3 the employment of $\alpha-2$ adrenoceptor agonist for sweetening of peripheral nerve blocks has added a brand new dimension to their clinical application. 4 the flexibility of Clonidine to scale back the indefinite quantity needs of ancient anaesthetic and analgesic agents is more and more getting used in perioperative amount. Clonidine, once combined with a neighborhood anaesthetic, has been found to increase the length of nerve block.5 it's been postulated that this action can be because of native constriction or facilitation of $\mathrm{C}$ fibre blockade.

\section{Materialandways}

The study was conducted on sixty patients with yankee Society of Anaesthesiologists (ASA) I and II adult of either sex, belowgoing higher limb surgery under supraclavicular plexus brachialis block. all of them underwent a radical pre anaesthetic analysis. In gift study, we tend to enclosed all the patients of higher limb surgery satisfying the inclusion and exclusion criteria throughout the amount of 1 year w.e.f January,2013 to Dec,2013. Exclusion criteria was:Patients age <18 yrs or over sixty years. Patients receiving anticoagulants, $\beta$ - blockers or opioids, on chronic analgesics, infection or any swelling on the aspect of block. Patients with history of pressure level|cardiovascular disease\}, myocardial infarct, drug abuse, pregnancy, psychiatrical disorder, DM, contralateral spinal nerve palsy, medical specialty deficit, cardiac, metabolism, viscus and/or kidney failure, peripheral pathology or hypersensitivity to anesthetic agent agents.

\section{PreparationAndPosition}

After shifting the patient to the operation theatre, associate degree endovenous access was obtained and ringer give started and inj. Ondansetron four mg endovenous was given. Patient was created to lie supine on the OT table and routine observation leads were applied. Baseline values of vital sign, blood pressure, SpO2, ECG and rate of respiration were recorded. the pinnacle was turned away to the alternative aspect by $30^{\circ}$ on feel the interscalene groove. The ipsilateral 
arm was adducted. The interscalene groove was palpated at its lowest purpose and therefore the purpose of most intensity of arterial blood vessel was set. The plexus brachialis was set with the nerve surveyor pen. A nerve surveyor needle (Stimuplex ${ }^{\circledR}$ A, B Braun) was directed simply on top of and posterior to the bone pulse and directed backwards and medially. Once the specified twitch was obtained and so reducing the present till the muscle contractions occur at a zero. 5 $\mathrm{mA}$ current level. This was taken because the confirmation of the proximity to the plexus brachialis. The needle was then control immobile and $1 \mathrm{ml}$ of the anesthetic agent answer once rigorously aspiration was injected. At now the twitch disappeared. The mechanism for the immediate disappearance of the twitch isn't a results of the anesthetic agent obstruction the nerve, however the mechanical displacement of the nerve far from the needle tip.

\section{StatisticalAnalysis}

Data were summarized as mean \pm variance or as percentages. Comparison of categorical variables between the 2 teams was done by Chi-square take a look at or Fisher's actual take a look at, as acceptable. Numerical variables were ordinarily distributed and were compared by Student's mismatched ' $\mathrm{t}$ '-test. All analyses were two-tailed and $\mathrm{P}<0.05$ was thought-about statistically vital.

\section{Results}

This prospective single blind study was conducted on sixty patients getting on eighteen to sixty years denote for varied higher limb surgeries and at random allotted into 2 equal teams of thirty every. Table-1 shows demographic profile of the studied teams and distinction was found to be statistically insignificant(p>0.05). As shown in Table two, the onsets of each sensory and motor block were considerably shorter and durations were considerably bigger within the cluster receiving Catapres. The pre-operative mean vital sign was eighty three.86 $\pm 7.99 / \mathrm{min}$ in blood type and eighty five. $13 \pm 10.58 / \mathrm{min}$ in type B. The distinction was statistically insignificant $(p>0.05)$.

\section{Discussion}

In the gift study, the time of sensory onset was shortened in type B, mistreatment fifty $\mu \mathrm{g}$ of Clonidine with Bupivacainewith a mean solar time of seven. $68 \pm 1.94$ min. The onset of motor 


\section{PHARMACEUTICAL RESEARCH}

blockade in blood type was sixteen.97 \pm 3.17 minutes and in type $B(12.87 \pm 3.39)$ minute. The distinction between the 2 teams was statistically vital $(p<0.0001)$. It is ended that the addition of Clonidine fifty $\mu \mathrm{g}$ shortened the onset time and so chop-chop made sensory and motor block. Our results for the onset and length of sensory and motor block don't tally with the results of the study conducted by Sarita S Hindoo et al10, who compared Clonidine with dexmedetomidine as associate degree adjuvant to thirty five cc of zero. $25 \%$ bupivacaine for supraclavicular block and reportable that the onset of sensory and motor blockade (clonidine group) was [(2.33 \pm 1.2$)$ and (3.87 \pm 1.78$)]$ min severally (too short). To my mind, I cannot attribute the other reason for this discrepancy except paltry pharmacological distinction between racemic and $\mathrm{S}(-)$-enatiomer of bupivacaine.

\section{Conclusion}

From the results of the current study it is ended that the anesthetic agent Bupivacainecould be a appropriate drug for supraclavicular plexus brachialis block, provides an extended length of pain free amount and with minimum disturbances on hemodynamic variables. The addition of fifty $\mu \mathrm{g}$ of Clonidine as associate degree adjuvant to Bupivacaineprolongs the length of sensory and motor block and at constant time shortening the latency (onset) amount. The drug alone or together with Clonidine produces terribly token aspect effects of no clinical significance. therefore we tend to suggest the incorporation of Clonidine as associate degree adjuvant to native

anesthetics.

\section{References}

1. AdmirHadzic, Hun Vloka. Peripheral nerve blocks:Principles and Practice- ny faculty of anesthesia.

2. PC, Cwik JC, Vallesteros F. Bupivacaine- a brand new long anesthetic agent agent. A preliminary clinical and laboratory report. AnesthAnalg.

3. Dejong RH. Axillary block of plexus brachialis. medicine.

4. Murphy DB, Paul McCartney CJ, Chan VW. Novel analgesic adjuncts for plexus brachialis block: a general review. AnesthAnalg2001.

5. Singelyn FJ, Gouverneur JM, Robert A. A minimum dose of Clonidine added to mepivacaine prolongs the length of physiological condition and physiological condition once axillary plexus brachialis block. AnesthAnalg 1998. 


\section{THE AMERICAN JOURNAL OF}

\section{PHARMACEUTICAL RESEARCH}

6. Kosugi T, Mizuta K, Fujita T, Nakashima M and Kumamoto E. High concentrations of dexmedetomidine inhibit compound action potentials in frog sciatic nerves while not a2adrenoceptor activation. Br J Pharmacol2000.

7. Raj PP, Rosenblatt R, Montgomery SJ. Use of the nerve stimulator for peripheral blocks. RegAnesth 1990. 